\title{
A "PALAVRA DIVINA" COMO LOGOS SEPARADOR
}

\author{
Elaine Pedreira Rabinovich \\ Lívia A. Fialho Costa
}

RESUMO. Este estudo indaga quanto às implicações do uso da "Palavra de Deus" por meio da leitura da Bíblia na vida cotidiana de evangélicos brasileiros. Vinte entrevistas foram realizadas com famílias evangélicas na cidade de Salvador (Bahia) com o objetivo de compreender quais as consequiências da conversão na sua vida pessoal e familiar, atentando-se para os motivos da adesão à crença pentecostal. A análise das entrevistas seguiu uma abordagem fenomenológica interpretativa. Os resultados evidenciaram que a adesão a uma Igreja Evangélica, como ocorre atualmente no Brasil, re-direciona a vida familiar por meio da inclusão de um terceiro termo: Deus e/ ou a Palavra de Deus - com quem os participantes começam a "conversar" a partir de suas leituras da Bíblia. Desta forma, emergem conceitos na vida cotidiana dessas pessoas que proporcionam um "modo de vida" que permite o planejamento de metas e a emergência de um futuro desejado e planejado.

Palavras-chave: Relações familiares; evangélicos; palavra de Deus.

\section{GOD'S WORD” AS A SEPARATING LOGOS}

\begin{abstract}
This study inquires about the implications if the use of "God's words" by means of the lectures of the Bible in the Brazilian evangelic daily life. Twenty interviews were conducted with Evangelical families that lived in the city of Salvador, Bahia, Brazil. The study investigated when and why the adherence to Evangelical beliefs happened and what consequences it brought to personal and family life. Analysis followed the phenomenological interpretative method. Results showed that adherence to an Evangelical Church, as it currently occurs in Brazil, re-directs family life through the inclusion of a third term: God and/or God's word - to whom the participants start to "talk" from their reading of the Bible. Thus, some "concepts" emerge in those people's daily life that provide a "lifeway", allowing the planning of goals and the emergence of a desired and planned future.
\end{abstract}

Key words: Family relationships; evangelic; God's word.

\section{LA PALABRA DIVINA" COMO LOGOS SEPARADOR}

RESUMEN. Eso estudio se pregunta sobre las implicaciones del uso de la "Palabra Divina" por medio de lecturas de la Biblia en la vida cotidiana de evangélicos brasileños. Veinte entrevistas fueran realizadas con familias evangélicas de la ciudad de Salvador, Bahía, adonde se preguntó cuando y porque ocurrió la adhesión a las creencias pentecostales y cuales consecuencias esas tuvieran para la vida familiar y personal. Las entrevistas fueran analizadas según el método fenomenológico interpretativo. Los resultados mostraran que la adhesión a una Iglesia Evangélica, como ocurre hoy en el Brasil, fornece una nueva dirección la vida familiar por medio de la inclusión de un tercero término: Dios e/o la palabra de Dios - con quién los partícipes empiezan a "hablar" debido a sus intensas lecturas de la Biblia. De esa manera, algunos "conceptos" emergen en la vida cotidiana de esas personas proporcionando un "modo de vida" que permite la planificación de metas y la emergencia de un futuro deseado y planeado.

Palabras-clave: Relaciones familiares; evangélicos; palabra de Dios..

Este estudo indaga quanto às implicações do uso da "Palavra de Deus", especificadamente da leitura da Bíblia, na vida cotidiana de evangélicos brasileiros.
Freston (1994), numa tentativa de resumir a história de inserção de grupos evangélicos no território nacional, mostra que três momentos, ou três ondas,

Doutora em Psicologia Social. Professora e pesquisadora no Programa de Pós-Graduação em Família na Sociedade Contemporânea (UCSAL).

\# Doutora em Antropologia Social e Etnologia. Professora e Pesquisadora nos Programa de Pós-Graduação em Família na Sociedade Contemporânea (UCSAL) e Pós-graduação em Educação e Contemporaneidade (UNEB). 
marcam tal movimento de instalação. São, assim, momentos em que a Palavra evangelizadora pentecostal ganha força através de denominações expressivas: a primeira, na década de 1910, trouxe a Congregação Cristã e a Assembléia de Deus; entre os anos 50 e 60, três grandes grupos: a Quadrangular, Brasil para Cristo e Deus é Amor, representam a segunda onda decorrente de mudanças no Brasil e no mundo; finalmente, no final dos anos 70, e ganhando força nos anos 80, chegam a Igreja Universal do Reino de Deus e a Igreja Internacional da Graça de Deus.

Essas gerações de igrejas trouxeram atualizações teológicas, litúrgicas, éticas e estéticas, aproximandose da vida cotidiana e dos anseios de uma população urbana caracterizada pela pobreza/exclusão. Conforme os dados do IBGE - Instituto Brasileiro Geográfico e Estatístico (2000), o crescimento evangélico foi quatro vezes a média populacional: $16 \%$ dos brasileiros professavam o credo evangélico, enquanto em 1980 eram $8 \%$; 18 milhões pertenciam às denominações pentecostais, carismáticos e neopentecostais e 8 milhões a denominações tradicionais e históricas. 1200 denominações, distribuídas em 188 mil templos evangélicos, possuem 300 emissoras de rádio, 90 programas de TV, representando $80 \%$ da programação religiosa no Brasil. A menor presença evangélica no país está no Nordeste (10,3\%): no Centro-Oeste, alcança $19,1 \%$.

Desde fins dos anos 1990, esta expansão tem sido objetivo de discussão em nível nacional e acadêmico. Silva (2007), por exemplo, atribui o seu sucesso a terem essas igrejas se apoderado de uma matriz identitária pré-existente, ligada aos cultos do Candomblé e Espíritas, acrescentando a ela elementos modernizadores como: valorização do pragmatismo, gestão empresarial na condição dos templos, ênfase na teologia da prosperidade, utilização da mídia para o trabalho de proselitismo em massa e de propaganda religiosa - as chamadas "igrejas eletrônicas" -, e a centralidade da teologia da batalha espiritual contra as outras religiões, sobretudo as afro-brasileiras e o espiritismo. Esse autor supõe ser esta uma estratégia para atrair fiéis ávidos pela experiência de religiões com forte apelo mágico, extáticas, com a vantagem da legitimidade social conquistada pelo campo religioso cristão.

$\mathrm{O}$ presente estudo originou-se de uma pesquisa qualitativa sobre processos de nomeação de vinte famílias evangélicas em que um dos tópicos abordados foi a relação entre a conversão e suas vidas (Rabinovich, Franco \& Costa, 2008). As respostas revelaram ter ocorrido uma total mudança de vida, "uma mudança de mundos" a partir do evento da conversão. Corroborando o que a literatura especializada em evangélicos mostra, no que diz respeito à dimensão espetacular e milagrosa da experiência, sujeitos que se tornam fiéis após terem descoberto a "Palavra" ou terem saído do "mundo da escuridão".

A partir desses relatos, emergiu a hipótese de que a "Palavra de Deus" era um terceiro termo entre os mundos $\mathrm{Eu} /$ Outro, adquirindo a função de um organizador para as pessoas entrevistadas. Tal hipótese está de acordo com a acepção da palavra sagrado. "O significado do conceito 'do sagrado' na linguagem sagrada é separação (...). Ser sagrado é, em essência, ser outro bem diferenciado" (Steinsaltz, 1992, p. 67). A Palavra é uma categoria "hipersemantizada" entre os fiéis, emprestando-se a várias acepções e abrindo espaço para ações que podem durar no tempo, contribuindo para o estabelecimento de uma nova pessoa. Um crente ou um cristão - como normalmente se auto-intitulam os convertidos às diversas denominações evangélicas ou neoevangélicas no Brasil - é um divulgador, por excelência, do projeto de Deus na terra (a Palavra); embaixo do braço ou nas mãos, como escudo, leva a Bíblia como acessório de apoio, de onde retira as Palavras consoladoras e se comove lendo salteadamente versículos cuja interpretação literal permite-lhe um conforto, para além daquele sugerido nos templos durante os cultos; a Palavra é, assim, ao mesmo tempo, instrumento e catalisador de boas condutas. Aquele que difunde a Palavra torna-se diferente porque separado dos Outros comuns, alheios à determinação da chegada de outros tempos.

Várias questões podem ser dimensionadas quando o tema é motivo de conversão. Um conjunto de análises, por exemplo, produzidas no âmbito dos trabalhos e pesquisas empíricas do Mestrado em Família na Sociedade Contemporânea, vêm demonstrando como a experiência corporal - ou o 'sentir-se tocado pelo Espírito' (Costa \& Jacquet, 2006) - deve ser considerada como categoria analítica para a compreensão da conversão e permanência em denominações evangélicas. As experiências emotivas, o êxtase durante os cultos entusiásticos, são elementos importantes no processo de redefinição identitária religiosa, ao tempo em que são, para o fiel, condições que apontam sua aceitação perante Deus como pertencentes à comunidade de verdadeiros fiéis.

No entanto, a ênfase do presente trabalho está em que a hipótese proposta - a de que a "Palavra de Deus" emerge como um terceiro termo, equivalendo à imposição de uma "ordem simbólica paterna" -, remete a outra discussão. Esta deriva do conceito de 
"logos separador" e do conceito de self dialógico em sua relação à necessidade ou não de um terceiro termo na constituição dialógica do Eu e do Outro.

O termo "logos separador" está associado à teoria psicanalítica em que pela introjeção da "Palavra do Pai", ou de uma "ordem simbólica", teria ocorrido uma emancipação do sujeito como autônomo. Para Roudinesco (2002), Freud propôs uma teoria do poder centrada em três imperativos: necessidade de um ato fundador (o crime), necessidade da lei (a sanção), necessidade da renúncia ao despotismo da tirania encarnada pelo pai da horda selvagem. A esses três imperativos correspondem três estados da história das sociedades e das religiões, e da evolução psíquica do sujeito. No período animista, o homem se atribui uma onipotência que é um equivalente ao narcisismo infantil. Na fase religiosa, ele delega o poder a Deus, como a seus pais durante o complexo de Édipo. $\mathrm{Na}$ época científica ou espiritual, ele a projeta sobre um logos - o logos separador -, separando assim a razão de todo objeto fetiche, equivalendo à instalação de uma ordem simbólica. Para essa autora, este logos interiorizado pode ser visto como reconduzindo a uma ordem patriarcal ainda mais autoritária porque dissimulada como uma consciência culpável.

$\mathrm{O}$ conceito de self dialógico, segundo o seu proponente, Hermans (1999), pode ser descrito em termos de uma multiplicidade dinâmica de posições do $\mathrm{Eu}$ - I positions - relativamente autônomas. Segundo esse autor, o Eu se move espacialmente de uma posição a outra de acordo com mudanças no tempo e na situação, tendo a capacidade de dotar cada posição de uma voz de modo que relações dialógicas entre posições podem ser estabelecidas. As vozes funcionam como personagens em uma história, num processo de pergunta e resposta, acordo e desacordo, resultando em um self complexo, narrativamente estruturado.

Gillespie (2007) enfatiza a base social da "autoreflexão". Para esse autor, nomear, i.e., usar um mediador semiótico para apreender uma experiência afetiva ou uma situação, distancia a pessoa daquela experiência e situação. Sistemas semióticos seriam arquiteturas de intersubjetividade que possibilitam a tradução entre as perspectivas do ator e do observador no ato social, o que seria a pré-condição para a autoreflexão, presente em "audiências invisíveis".

Igualmente Markova (conforme Salgado \& Gonçalves, 2007), baseada em Bakhtin, tem insistido em que a diferenciação eu/ outro envolve uma terceira parte. Para Salgado e Gonçalves (2007), enquanto o Eu ocupa o centro da experiência aqui-e-agora, afetivamente envolvido no processo de se dirigir ao
Outro, a relação estaria sendo mediada simultaneamente por uma terceira parte "invisível". Na concepção triádica, a intersubjetividade implica em uma audiência invisível, tão presente quanto o Outro, ambas antecipadas à realização do ato ou da fala, o que resulta "em um ato complexo de resposta a uma justaposição dinâmica de várias vozes questionadoras" (Salgado \& Gonçalves, 2007, p. 614).

Estas "audiências potenciais invisíveis" estão sendo aqui supostas constituídas no discurso dos entrevistados, ao menos em parte, pela "Palavra de Deus". Nestes discursos, esta terceira parte pode ser compreendida como:

1. "A Palavra de Deus" funcionaria como um "logos separador" que, ao separar os termos eu/ outro, permite reflexão e/ou consciência, e uma consciência diferencial de si e do outro.

2. Esta operação não ocorreria em termos puramente lógicos dado possuir a qualidade/ conteúdo daquilo que a pessoa projeta Nele. Essa projeção adquire o caráter de onipotência, onipresença, onisciência, enfim, todas as qualidades Dele, que passam a ser "compartilhadas" com o crente.

3. O conteúdo propriamente emocional da conversão, conforme experienciado no corpo e nas graças recebidas, estabeleceria a conexão afetivo/ cognitiva, possibilitando as mudanças cognitivas ora em pauta.

\section{MÉTODO}

Vinte entrevistas semi-estruturadas foram realizadas com famílias evangélicas de Salvador, Bahia. Foram entrevistados três pais, dezesseis mães e um casal. Após a sua aceitação quanto à participação no estudo e a assinatura de um termo de Compromisso Livre e Esclarecido, foi realizada a entrevista através da qual inquiria-se, entre outras questões, sobre o processo de conversão (quando e porque) ao pentecostalismo e as conseqüências para a sua vida pessoal e familiar. Os depoimentos foram registrados em fita magnética e posteriormente transcritos.

As famílias entrevistadas pertenciam às seguintes denominações: tradicionais (5); pentecostais: $1^{\mathrm{a}}$ onda (5), $2^{\mathrm{a}}$ onda (5), $3^{\mathrm{a}}$ onda (5).

As entrevistas foram analisadas de acordo com os princípios que norteiam as técnicas de análise fenomenológica interpretativa (IPA) (Smith \& Dunworth, 2003) cujo objetivo é explorar em detalhe o ponto de vista do participante a respeito do tópico em questão. Ela se distingue da análise fenomenológica por conceber o exercício da pesquisa 
como um processo dinâmico, onde o pesquisador interfere com as suas próprias concepções.

Será apresentado a seguir, como corpus deste trabalho, um relato que exemplifica como os conceitos derivados da participação em uma denominação religiosa modificaram a vida da depoente e, em seguida, categorias de análise derivadas dos relatos dos vinte entrevistados. Finalizando este estudo, algumas reflexões buscam interpretar os achados à luz de modos brasileiros de subjetivação, sóciohistoricamente concebidos.

\section{RESULTADOS E DISCUSSÃO}

\section{Apresentando o relato}

Trata-se de uma mulher de 35 anos, casada, com uma única filha, cabelereira como profissão, moradora em Salvador, convertida à igreja Assembléia de Deus. Este caso foi escolhido por elucidar como a separação e a individuação ocorre a partir da adesão a uma fé em que a leitura da Palavra Divina fornece os elementos cognitivos tanto de estruturação lógica quanto de conteúdos éticos e pragmáticos. Em seu relato, retrata a fé como um destinar que dá um rumo.

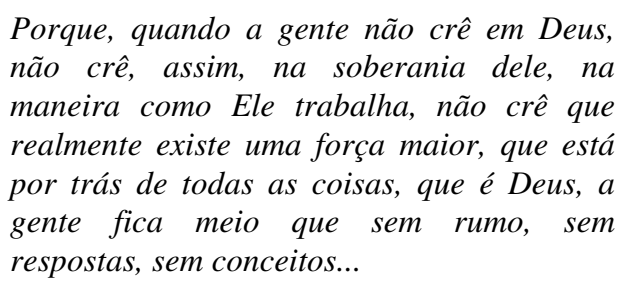

O ponto crucial nesse relato está em uma mudança cognitiva, um aprendizado, ocorre a partir da leitura da Bíblia, em que conceitos permitem organizar e ordenar a vida, dando a ela um rumo, uma direção.

Então muitos conceitos, muitas visões erradas, elas foram sendo modificadas, e eu fui aprendendo a conhecer o contexto da vida num todo.

Esses conceitos possibilitam mudanças e fornecem uma estrutura, pessoal e familiar, da vida como um todo. A (re)elaboração dos conceitos se dá, normalmente, a partir do momento em que o fiel 'Aceita a Palavra', uma condição que, em algumas denominações evangélicas, pode significar o ritual de apresentação do novo convertido à comunidade religiosa, quando este dá o seu testemunho público de fé mediante relato das graças e glórias alcançadas; o batismo por imersão e o batismo de fogo são igualmente - e hierarquicamente os mais importantes - rituais de acolhimento do verdadeiro cristão.

A gente fica sem estrutura familiar, entendeu. E eu percebi que, dessa época para cá, muita coisa na minha vida mudou porque conceitos foram formados na minha vida, conceitos ou que não existiam, ou que estavam errados.

A entrevistada aponta como a fé funciona como um ancoradouro e um porto, mas também como uma auto-identificação por diferenciação, como um si próprio único. Os conceitos funcionam como um terceiro vértice entre ela e o mundo, levando-a a diferenciar-se.

Porque aí o problema é que quando a gente não está agarrada a nada, não tem nada onde se ancorar, onde buscar socorro, a gente acha que é mais um na multidão, e não é bem assim que funciona. Cada um de nós tem uma importância ímpar, somos elementos num grupo social, num contexto, numa humanidade, mas somos, cada um de nós tem um valor ímpar.

Estabelecido o triângulo, os sentimentos de unicidade/ diferenciação e de importância parecem sustentar, por sua vez, a própria fé, fazendo surgir a consciência.

E a partir do momento que a gente tem essa consciência, a gente acredita que nós não fomos feitos por um acaso, por um acidente, por um descuido, que nossa vida ela tem um propósito, entendeu, e dentro desse propósito a gente procura viver o mais consciente possivel; procura, dentro de nossas limitações, porque somos homens falhos, imperfeitos, mas dentro de nossas limitações procuramos sempre estar no equilíbrio, num meio termo.

$\mathrm{O}$ pertencimento ao grupo religioso a estruturou conceitualmente, como ela diz, colocou conceitos e palavras - ou seja, vozes - com as quais pode dialogar. Reflete sobre a sua vida como em um filme com personagens, como uma narrativa - onde o passado se torna presente e o presente se projeta no futuro, inclusive no futuro da filha.

(Estava separada e) Veio a fazer com que eu viesse a refletir muita coisa. Pensando nas coisas que nós vivemos de boas e de ruins, porque é o aprendizado, até nas coisas ruins a gente aprende muita coisa. Então eu 
pude... como um filme,, visualizar as situações e ver aonde eu errei, aonde eu poderia ter me controlado mais, sido mais lúcida, ponderado mais as coisas, relevado, ceder, e, até quando a gente está com razão, tem que saber passar isso para a outra pessoa para não ferir. E esse tempo fez com que nós pensássemos muito acerca disso. Então agora a gente está numa fase de reinício de relacionamento, e sendo o foco nosso principal a nossa filha, porque... por mais forte que ela seja a gente sabe que abala, e o nosso objetivo principal é que ela não venha a sofrer conseqüencias futuras

A Palavra Divina conforme inserida no seu meio social religioso parece funcionar como uma terceira voz que passa a narrar o filme para ela. Essa narrativa é a auto-reflexão onde ela conta outra história a respeito de si própria, uma espécie de versão - nem mais nem menos verídica do que as outras - revista e adaptada à nova condição de mulher crente, fiel aos princípios da Igreja e obediente a um Deus que é, antes de mais nada, o seu protetor e provedor simbólico.

(A conversão) Influencia bastante. Eu creio assim, que... quando Jesus entra na vida da gente, tudo muda. Todas as áreas da nossa vida mudam, nosso trabalho, nosso relacionamento. Eu era uma pessoa muito de enfrentar e não querer saber quais serão as conseqüências. Não parava para ponderar as coisas.

Deus surge como uma meta, um horizonte, um terceiro a dialogar, e isto permite essa "concepção" de si própria.

Deus, ele não muda a personalidade de ninguém. Mas Ele traça uma meta dentro da nossa vida, que a gente aprende a controlar os nossos impulsos. Valorizar aquilo que é bom, e dominar aquilo que não é tão bom. Aprender a conviver com aquilo que não é tão bom. Tanto em nós como nos outros.

O processo de conversão, basicamente pela intermediação de conceitos, possibilita a aquisição de uma visão, de uma perspectiva, de um rumo, que permitem avaliar, programar, analisar, postergar, enfim, sair do imediatismo. O que possibilita essa visão é a interlocução propiciada pela leitura da Bíblia.

A conversão muda bastante! A base do evangelho é mudança de vida, é mudança para melhor. Os conceitos... Tudo para melhor... de uma forma mais sadia, mais madura, entendeu? (....) no meu trabalho, eu hoje procuro sempre ponderar muito, eu hoje procuro sempre analisar, intermediar as situações... então, tudo isso faz parte desse processo. A visão, minha visão foi aberta, está de uma forma diferente. Então eu procuro muito analisar as coisas....

Assim, a visão da entrevistada, ampliada temporal e espacialmente, foi adquirida pela interlocução com as palavras divinas e pelo diálogo interno.

\section{APREENSÃO DE CATEGORIAS DE ANÁLISE A PARTIR DAS EXPERIÊNCIAS RELATADAS}

Outros elementos que emergiram das demais entrevistas serão elencados a seguir. Deve-se enfatizar, contudo, que estão efetivamente interligadas entre si. Por meio de sua apresentação, pretendemos mostrar como os conceitos advindos do pertencimento a uma denominação são apropriados na vida cotidiana.

\section{Deus como criador do mundo e de todas as coisas}

Trata-se de um princípio aceito como dogma em todas as entrevistas. $\mathrm{O}$ interesse está em sua incidência em coisas muito distantes de tal criação, como a de criar empregos.

\section{Quem criou o nosso emprego? Foi Deus}

$\mathrm{O}$ fato de ser uma criatura do criador, conferindo a primazia a Ele, implica em uma espécie de vínculo, ou mesmo institui uma espécie de "barganha cósmica" (Figueiredo, 1995). Além disto, Costa e Jacquet (2006) enfatizam como, por meio da conversão, as mulheres "resolvem" questões emocionais associadas à dor, à angústia, ao medo, a perdas, à insegurança etc.: se Deus tudo criou, pode criar o que a pessoa está necessitando.

Foi muito bom ter aceitado Jesus desde os 18 anos, ter conhecido a Palavra de Deus, ter servido e continuar servindo esse único Deus, que supriu todas as minhas necessidades.

\section{Deus como Todo Poderoso}

Trata-se de um poder tão poderoso que o homem, ao se entregar a Deus pela fé, adquire algo desse poder. 
Eu posso (ter o emprego)! Ele é quem me fortalece, é a certeza que Ele coloca em nosso coração, de dizer a coisa com convicção e sem dúvida, e Ele nos diz todos os dias: não temas porque estou contigo. (...) Ter a vitória em nome Dele.

Só você realmente conhecendo a Palavra de Deus, é que você tem essa Graça, essa força para você poder (...)

Aí comecei a ver o poder de Deus na minha vida. Quando comecei a ver, aquele vazio foi preenchido.

Assim, o sentimento de impotência e de estar "atirado ao mundo" encontra um alento e um amparo que passa a fornecer sustentação para ações no mundo. E, como a Deus não se pode enganar, porque Ele é Onipresente, isso permite um pacto consigo próprio e a realização de metas.

\section{Porque pacto com homem você pode enganar, mas com Deus não pode}

O sinal do poder Divino é igualmente divino e diferenciador das pessoas, permitindo estados de bemestar e de distinção, pessoal e social.

Gosto de ler a Bíblia, sei que tenho o dom de ajudar as pessoas e até já recebi o dom de língua. O Espírito Santo me usou. Eu estava em sintonia com o céu. Me senti abençoada!

\section{A Palavra de Deus como resolução de problemas}

Um dos aspectos da adesão a uma crença está ligado a questões de saúde. Como uma entrevistada relata, trata-se de uma cura por meio de um diálogo aberto, imediato, pleno de significado.

E quando vi, na igreja, fiquei curada. Tem que ter fé em Deus. Nas orações ele responde a você. Não é: "vou pensar, me aguarde na fila”. Entendeu? Hoje, eu tenho alegria, eu sou alegre. É porque nós vivemos a Palavra.

O engajamento dos fiéis à Igreja os faz valorizar atitudes racionais frente à vida cotidiana. "Neste sentido, não é simplesmente a cura mágica, imediata, ou o êxtase propiciados pelo culto que garantem a conversão do fiel: é antes uma valorização de si e a busca de soluções práticas e estratégicas (...)" (Costa \& Jacquet, 2006, p. 90). Ao enfatizar o papel do corpo e das emoções na conversão, essas autoras mostram que ser tocado por Deus é um evento que inaugura o processo de reflexão e tomada de atitudes racionais perante a vida cotidiana. "A Igreja trabalha em uma lógica discursiva que articula dois conteúdos (mágico e ético) que estão sempre em uma relação de complementaridade" (Costa \& Jacquet, 2006, p. 90).

Tal acesso pode permitir a realização de desejos e de necessidades, e a direção quanto a decisões pessoais envolvendo questões familiares como o casamento.

Aí eu escrevi pra Deus, num papel. Depois de muito tempo eu fui achar este papel. Escrevi como eu queria meu marido, com detalhes. Assim graças a Deus, Ele me honrou mais uma vez. Ele me apresentou uma pessoa maravilhosa. Meu marido é uma benção.

(...) e casamento é uma coisa de muita... muita responsabilidade e a minha preocupação foi essa(...) temos que orar pra saber se Deus está no negócio e, em meio à oração, recebi a confirmação de Deus: orando, jejuando, pedindo conselho.

Se eu não fosse cristão hoje e aplicasse os princípios da Bíblia, tanto eu como ela. Eu, por exemplo, antigamente bebia demais $e$ ficava nervoso, não gostava de ficar em casa, e antigamente, eu tinha muitas namoradas (...). e eu vejo pela força que estou hoje, eu consegui contornar os problemas que tem no casamento. Até mesmo a Bíblia diz, aquele que coloca os princípios bíblicos na vida, viverá em paz, e eu tenho usufruído dessa paz que a Bíblia fala.

Em seu estudo sobre habilidades conjugais e religião, Villa, Del Prette e Del Prette (2007) concluíram que os presbiterianos mostraram-se mais enfáticos na tarefa de associar ensinamentos a habilidades sociais do que os católicos, sugerindo, contudo, investigações maiores quanto ao relacionamento conjugal e familiar. Neste sentido, dentre as três principais dimensões apontadas por Mosmann, Wagner e Feres-Carneiro (2006) para a auto-avaliação da qualidade conjugal - o contexto, os recursos pessoais e os processos adaptativos - pode-se perceber, nas falas acima, a adesão à crença como um elemento que fortalece: o contexto, no caso em que ambos os cônjuges pertençam a uma mesma denominação; os recursos pessoais, pelo significado do poder divino como um aliado; e os processos adaptativos engendrados pela adesão religiosa, quando não se tornam extremamente rígidos. 
Este uso do poder da Palavra se expande para áreas mais extensas e complexas.

A pobreza não é de Deus, as trevas não são de Deus, e sim do Diabo. Se você se sente perseguido, se você se sente angustiado, você tem que procurar a Palavra de Deus, porque é ela que vai resolver o seu problema.

Igreja não salva, não salva nem liberta ninguém, quem liberta é Deus e o poder da Palavra.

Estas duas falas enfatizam a voz que assegura o poder da Palavra. Costa e Jacquet (2006, p. 90), ao apontar como "administrar o mal consiste em extirpar todos os traços contrários a um ideal de vida digno de redenção, cujos atributos são desenhados e elaborados no seio da Igreja e partilhados pelos membros", reforçam a noção da audiência invisível que inaugura uma ética, uma estética, um ideal de vida e de suas práticas.

\section{Deus como oportunidade de mudança}

A partir deste diálogo, abre-se uma oportunidade de mudança em que ambas as partes, Deus e a pessoa, cumprem um papel.

Deus não quer pessoas preguiçosas que só dizem “ Ah! Deus vai fazer por mim”. Eu fiz a minha parte e o Senhor abriu meus caminhos.

Observa-se aí a cumplicidade ou o pacto que resulta das várias mudanças de posição do Eu: pelo menos três "eus" se encontram nesta sentença: o da preguiçosa, o do Senhor e o do "mim". Há uma espécie de pacto, em que a retribuição vem na forma de saúde e prosperidade.

Antigamente eu achava que se nasci de um jeito, vou morrer desse mesmo jeito. Hoje não penso assim. Todo ser humano é digno de uma chance e eu tive essa chance, Deus me deu essa chance.

Aqui também se pode observar o jogo dialético e dialógico entre as várias posições assumidas pela pessoa.

Ela (Ana, a mãe de Samuel) continuou orando e Deus fez um milagre e concedeu o filho a ela. Ela poderia ter desistido de seu sonho ... mas sua fé era tão grande que Deus deu um milagre a ela. Essa história é parecida com a minha.

Este exemplo ilustra a identificação com as narrativas bíblicas como um modo de compreender a si próprio.

Já diz a Bíblia: procurar ver essa parte do passado como testemunho posterior, para dizer como nós éramos e como estamos hoje, como Deus nos mudou.

As mudanças obtidas comprovam o poder divino e, de uma maneira tautológica, o poder divino é comprovado pelas mudanças. Há como uma audiência silenciosa que reforça ambas as posições e conclusões: o dito na Bíblia.

\section{Deus como Conhecimento}

A gente vai conhecendo a palavra de Deus e vai se moldando. A gente precisa ler a palavra, conhecer... É isso que faz a gente conhecer Deus, conhecer Jesus e saber qual foi o significado dele morrer... Ele morreu pra salvar a gente. Nós temos que nos apegar a uma religião para poder suportar as coisas que estão acontecendo, tanta violência, assassinatos...

A Palavra Divina fornece os instrumentos para a mudança na medida em que o seu conhecimento permite o autoconhecimento. Observa-se, nesta afirmação, algo que estava presente em todas as demais: a figura de Jesus que dá significado, sendo um mediador semiótico que fornece sentido e salvação.

Tem que parar, pensar, pedir a Deus que nos tire essas coisas que não provêm Dele

Semelhantemente à questão de Deus e do Diabo, o Mal não vem de Deus, e pode ser afastado na medida em que somos criaturas de Deus. Essa voz tira algo da culpabilidade e aponta para saídas.

Conhecer a verdade, porque a Bíblia diz: "Conhecerei a verdade e a verdade te libertará".

A leitura da Bíblia, individual e compartilhada, traz em seu bojo um desejo de conhecimento visto como libertador. Esta expansão de horizontes talvez seja um dos elementos mais poderosos da força da Palavra, estando associada ao sentido etimológico de religião - religare - o que a une ao elo social e a uma solução concomitantemente coletiva e individual (Askofaré, 2008). 
A maioria das pessoas não quer pensar nisso. Você faz e vê se vai dar certo ou não. É assim: "Eu prefiro ter liberdade de fazer o que eu quero e, se não der certo, depois eu corro atrás". Aí a Igreja mostra que a probabilidade de tal coisa dar errado é grande, alerta.

Aí está descrito o ensinamento prático que decorre do conhecimento: o uso da ponderação, da lógica, do distanciamento, da auto-reflexão, como nas locuções abaixo:

Porque a gente que conhece a palavra de Deus, que temos um conhecimento dentro da Bíblia, sabemos que temos que ter a direção de Deus.

Aprendi e tenho aprendido muito com Ele, né? É(...) quem tem me dado sabedoria...pra resolver os problemas... pra enfrentar esse mundo...

A religião ensina a agir no espírito, entrar no espírito de oração e as coisas foram mudando.

Portanto, a adesão a tais crenças conduz, ou pode conduzir, a mudanças quanto ao modo de organização psíquica. Essa resulta, basicamente, em um fortalecimento da capacidade para suportar frustrações e para adiar a satisfação de necessidades dado o crente passar a "compartilhar" qualidades divinas, o que conduz a uma estruturação temporal não imediatista. Conforme apontado, religare implica em um encontro entre soluções individuais e coletivas, donde emergem a força do pertencimento e da valorização social. Assim, a "Palavra de Deus" como "logos separador" separa os termos eu/ outro, permitindo reflexão e/ou consciência, e uma consciência diferencial de si e do outro.

\section{REFLEXÕES FINAIS}

Uma reflexão de âmbito geral parece estar associada às crenças em geral, religiosas e não religiosas, que, como um sistema de relações de significados coeso e estruturado, permitem uma "audiência potencial" condensada no espaço. Essa audiência potencial seria o terceiro termo além do Eu e do Outro e, conforme evidenciado pelos excertos acima, no que se refere ao uso da Palavra de Deus como essa audiência, há um desenvolvimento interior baseado igualmente no reconhecimento do Outro.

Se observarmos do prisma da nomeação, seria como se, simultaneamente, várias gerações estivessem presentes em um nome, por ex. Moisés, que funcionaria como um atrator para as forças que o geraram e como uma justaposição dinâmica de várias vozes questionadoras.

Ao considerarmos a adesão a uma crença que para uma pessoa representa a resposta global às suas perguntas, poderemos observar que esta crença funciona como uma "terceira voz" que permanentemente orienta, dirige, organiza, dá o rumo, às inquietações e à localização do Outro, inclusive do Eu. Esta "voz" é um elemento questionador, constituído de várias vozes oriundas das várias leituras sobre o tema, mas ao mesmo tempo, é um organizador "existencial" quanto aos fenômenos e à sua interpretação, ou seja, um formulador do signo mediador.

Uma segunda leitura dos casos apresentados se refere especificamente à realidade brasileira, embora possa ser estendida a segmentos populacionais de outros países. O Brasil, por circunstâncias sóciohistóricas cuja explicação foge o escopo deste trabalho, não passou pelas transformações necessárias à emergência da "modernidade", como, e ao mesmo tempo em que, nos países europeus e mesmo norteamericanos. A transplantação de idéias "fora do lugar", importadas de fora, não possibilitou a constituição de um ser "moderno", de um "sujeito autônomo" (Figueiredo, 1995). Por seu lado, a monarquia, tendo se instalado no país e aqui se mantido de forma sui-generis nas Américas, gerou estruturas do poder político como um centralismo monárquico, o que significou

$$
\begin{aligned}
& \text { a herança de uma das culturas mais atrasadas } \\
& \text { da Europa, favorecendo a prevenção de } \\
& \text { rupturas sociais, culturais e econômicas, um } \\
& \text { excesso de centralização política e } \\
& \text { conservadorismo social (Haag, 2008, p. 84). }
\end{aligned}
$$

Apenas na segunda metade do século XX, podese dizer ter ocorrido a chegada ao Brasil da "Reforma" e da Ética Protestante no que estas significaram a valorização do esforço do trabalho e da prosperidade. A possibilidade de um acesso direto à Palavra de Deus, sem intermediários, ao direito de ter lucros, e outras "conquistas" protestantes representariam, para o homem e mulher brasileiros do século XXI, o que elas representaram, na reforma luterana, no século XVII: a queda do império monárquico absolutista e do poderio da igreja católica, a valorização da ação no mundo, a saída de soluções imediatistas associada à colocação de metas, ou seja, a entrada no que se convencionou chamar "Idade Moderna". 
Perdida a via da modernidade no momento em que esta se instalava no Ocidente, a importação recente de seitas e igrejas norte-americanas permitiu a uma massa de indivíduos urbanos se "assujeitarem".

Tais movimentos propiciam e exigem experiências e modos de subjetivação muito mais individualizantes e 'subjetivantes que os proporcionados pelo catolicismo tradicional brasileiro (...) Trata-se de um assujeitamento em que ser livre é seguir a ética e a palavra de Deus (Figueiredo, 1995, p. 77-78).

Assim, o culto nas igrejas evangélicas, predominantemente pentecostais e neopentecostais conforme ocorre no Brasil, impele as pessoas que a eles aderem - cerca de 26 milhões, pelo Censo de 2000, crescendo exponencialmente a cada ano - a entrar na modernidade, a se tornarem um "sujeito" em sentido freudiano. A freqüência a tais cultos conteria um equivalente do "poder paterno", ou seja, de um "corte" realizado pelo Logos de uma relação atávica, indiferenciada, com o grupo familiar de origem. Neste grupo de origem, as raízes emocionais predominam sobre as racionais, e o poder materno se sobrepõe ao paterno.

A "Palavra de Deus" equivale, pois, à Palavra do Pai, a que tira o mundo de um lugar "natural" para projetá-lo em um lugar "simbólico": o evento certo se torna o possível. Neste sentido, tais igrejas estão realizando uma "revolução" à sua maneira, principalmente destruindo a ordem sócio-simbólica em que a cultura brasileira estava ancorada.

Em resumo: a leitura consistente da Bíblia e o uso da Palavra de Deus pelos seguidores destas igrejas podem representar e substituir um poder paterno, criando no interior dessas pessoas diálogos, conceitos, com os quais não estavam acostumados a conviver e a ter, na forma de uma estrutura simbólica triádica. Esta constituição triádica pode equivaler tanto à operação de princípios lógicos quanto afetivos ao permitir canalizar as emoções e ordenar as idéias.

\section{REFERÊNCIAS}

Askofaré, S. (2008). Du nom-du-père au sinthome: Lacan et la religion. Estudos em Psicologia, 8(1), 03-13.
Costa, L. A. F. \& Jacquet, C. (2006). Emoção e experiência corporal na trajetória da conversão: um estudo de caso. Revista Bras Crescimento Desenvol Hum, 16(3), 83-91.

Figueiredo, L. C. (1995). Modos de subjetivação no Brasil e outros escritos. São Paulo: Escuta / Educ.

Freston, P. (1994). Breve história do pentecostalismo brasileiro. Em A. Antoniazzi \& C. L. Mariz (Orgs.). Nem anjos, nem demônios (pp. 67-159). Petrópolis: Vozes.

Haag, C. (2008). Um corte na história do Brasil. Pesquisa Fapesp, $143,80-85$.

IBGE (Instituto Brasileiro de Geografia e Estatística) (2000). Anuário Estatístico do Brasil. Rio de Janeiro: IBGE.

Gillespie, A. (2007). The social basis of self-reflection. In J. Valsiner \& A. Rosa (Eds.). The Cambridge Handbook of Socio-cultural Psychology (pp. 678-691). Cambridge: Cambridge University Press.

Hermans, H. J. M. (1999). Dialogical thinking and self-innovation. Culture \& Psychology, 5(7): 67-87.

Mosmann, C., Wagner, A. \& Féres-Carneiro, T. (2006). Qualidade conjugal : mapeando conceitos. Paidéia, 16(35). Recuperado em 04 de junho de 2008 em http://scielo.br/paideia

Rabinovich, E. P., Franco, A. L. S. \& Costa, L. A. F. (2008). Famílias evangélicas baianas e o processo de nomeação. Psicologia $e$ Sociedade, 20(3), 417-424.

Roudinesco, E. (2002). La famille en désordre. Paris: Fayard.

Salgado, J. \& Gonçalves, M. (2007). The dialogical self: social, personal and (un)conscious. In J. Valsiner \& A. Rosa (Eds.). The Cambridge Handbook of Sociocultural Psychology (pp. 608621). Cambridge: Cambridge University Press.

Silva, V. G. d. (2007). Neopentecostalismo e religiões afro-brasileiras: significados do ataque aos símbolos da herança religiosa fricana no Brasil contemporâneo. Mana, 13(1). Recuperado em 09 de dezembro de 2007 em http://www.scielo.br/scielo

Smith, J. \& Dunworth, F. (2003). Qualitative methodology. In J. Valsiner \& K. Connolly (Orgs.). Handbook of Developmental Psychology (pp. 603-621). London: Sage.

Steinsaltz, A. (1992). A rosa de treze pérolas: introdução à cabala e à fé judaica. (E. E. Horowitz, Trad.). São Paulo, SP: Maayanot. (Original publicado em 1980).

Villa, M. B., Del Prettte, Z. A. P. \& Del Prette, A. (2007). Habilidades sociais conjugais e filiação religiosa: um estudo descritivo. Psicologia Em Estudo, 12(1): 23-32.
Endereço para correspondência:
Pedreira Rabinovich. Rua Maranhão, 101, ap 101, CEP 01240-001, São Paulo-SP, Brasil. E-mail: elainepr@brasmail.com.br.
Recebido em 07/04/2009 Aceito em 18/11/2009 